\title{
Sensitive Spectrophotometric Method for Quantitation of Guaifenesin and Dropropizine in Their Dosage Forms
}

\author{
Ola M. Abdallah \\ Faculty of Pharmacy, October University for Modern Sciences and Arts, El Wahat Road, 6th October City, Egypt \\ Correspondence should be addressed to Ola M. Abdallah, olamody@yahoo.com \\ Received 17 February 2010; Accepted 11 May 2010 \\ Academic Editor: Maria Augusta Raggi \\ Copyright ( 2010 Ola M. Abdallah. This is an open access article distributed under the Creative Commons Attribution License, \\ which permits unrestricted use, distribution, and reproduction in any medium, provided the original work is properly cited. \\ Guaifenesin and dropropizine were analyzed through oxidation with periodic acid to give formaldehyde which was allowed to \\ condense with 4-Amino-5-hydrazino-4H [1,2,4]-triazole-3-thiol (AHTT). The condensation product was further oxidized to \\ yield a purple colored compound with maximum absorption at $550 \mathrm{~nm}$. Beer's law was obeyed in the range of $5-45 \mu \mathrm{g} \mathrm{mL}^{-1}$ \\ for guaifenesin and $10-80 \mu \mathrm{g} \mathrm{mL}^{-1}$ for dropropizine. Both drugs were also successfully determined in their dosage forms.
}

\section{Introduction}

Guaifenesin (GF), 3-(2-Methoxyphenoxy)-1,2-propanediol; is reported to increase the volume and reduce the viscosity of tenacious sputum and is used as expectorant for productive cough [1]. Different methods have been reported for the analysis of GF including HPLC $[2-8]$, GC $[9,10]$, capillary electrophoresis mass spectrometry [11], X-ray diffraction [12], voltammetry [13].

Dropropizine (DP), 3-(4-Phenyl-1-piperazinyl)-1,2-propanediol, is a cough suppressant reported to have a peripheral action in nonproductive cough [1]. Only two GCmass spectrometry methods have been reported for the determination of DP in biological fluids $[14,15]$ in addition to a manufacturer procedure that involves the determination of dropropizine by measuring its UV absorbance at $237 \mathrm{~nm}$ in $0.05 \mathrm{~N} \mathrm{HCl}$ (personal contact):<smiles>OCC(O)CN1CCN(c2ccccc2)CC1</smiles>

Dropropizine<smiles>COc1ccccc1OCC(O)CO</smiles>

Guaifenesin
Bromhexine $\mathrm{HCl}$ (BR), 2-Amino-3,5-dibromo-N-cyclohexyl-N-methylbenzylamine hydrochloride; N-(2-Amino-3,
5-dibromobenzyl)-N-methylcyclohexylamine hydrochloride:<smiles>CN(Cc1cc(Br)cc(Br)c1N)C1CCCCC1</smiles>

Bromhexine $\mathrm{HCl}$

The aim of the present paper is to develop a simple and accurate method for the determination of dropropizine and guaifenesin that permits their analysis in dosage forms without interference from excipients and other coformulated drugs.

\section{Experimental}

2.1. Chemicals and Reagents. Purpald or 4-Amino-5-hydrazino-4H [1,2,4]-triazole-3-thiol reagent (AHTT) (SigmaAldrich) was prepared as $0.5 \%$ in $0.5 \mathrm{M}$ hydrochloric acid. Periodic acid (Winlab, UK.) was prepared as $1 \mathrm{mg} \mathrm{mL}^{-1}$ 
solution in $0.2 \mathrm{M}$ potassium hydroxide. HPLC grade acetonitrile was from Fisher Scientific, UK. Potassium dihydrogen phosphate was from Sigma-Aldrich Chemie, Germany. All other chemicals used were of analytical grade and water was freshly distilled.

2.2. Materials. Reference standard guaifenesin (GF), dropropizine (DP) and bromhexine $\mathrm{HCl}(\mathrm{BR})$ were kindly supplied by Rameda Co. for pharmaceutical industries and diagnostic reagents, EVA Pharma for pharmaceutical and medical appliances and EVA Pharma for pharmaceutical and medical appliances, respectively.

\subsection{Pharmaceutical Preparations}

Muclear Capsules: It is a product of Rameda Co., Batch No. 08455 , claimed to contain $100 \mathrm{mg}$ guaifenesin and $8 \mathrm{mg}$ bromhexine $\mathrm{HCl}$.

Tussapine Lozenges: It is a product of EVA Pharma, Batch No. 602170 , claimed to contain $20 \mathrm{mg}$ dropropizine.

\subsection{Standard Drug Solutions}

Solutions of Guaifenesin: $0.1 \mathrm{mg} \mathrm{mL}^{-1}$ solution of GF was prepared in distilled water. Aliquots of this solution were diluted to produce working solutions of $5-45 \mu \mathrm{g} \mathrm{mL}^{-1}$.

Solutions of Dropropizine: $0.1 \mathrm{mg} \mathrm{mL}^{-1}$ solution of DR was prepared by in distilled water. Aliquots of this solution were diluted to produce working solutions of $10-80 \mu \mathrm{g} \mathrm{mL}^{-1}$.

Solutions of Bromhexine $\mathrm{HCl}: 0.1 \mathrm{mg} \mathrm{mL}^{-1}$ solution of BR was prepared in methanol. Aliquot of this solution was diluted to produce working solution of $50 \mu \mathrm{g} \mathrm{mL}^{-1}$.

\subsection{Instrumentation}

(i) Shimadzu UV/VIS 1602 Spectrophotometer.

(ii) Agilent 1200 series isocratic quaternary pump HPLC instrument connected to 1200 multiple wavelength UV detector (Germany). Separation was performed on $150 \times 4.6 \mathrm{~mm}$ Zorbax Extend-C18 column $5 \mu \mathrm{m}$ particle size (USA). Chromatographic peaks were electronically integrated and recorded using Chemstation software.

(iii) $\mathrm{pH} / \mathrm{mv}$ Meter with double junction glass electrode (Fisher, USA).

\subsection{General Procedure}

2.6.1. Calibration. One $\mathrm{mL}$ of each working solution of both drugs was transferred in a test tube, then $1 \mathrm{~mL}$ periodic acid was added. The mixture was left at room temperature for 15 minutes for GF and 20 minutes for DR, $0.5 \mathrm{~mL} 5 \mathrm{M}$ $\mathrm{KOH}$ solution was then added followed by $1 \mathrm{~mL}$ of AHTT solution. The mixture was shaken and allowed to stand for about 15 minutes for GF and 20 minutes for DR. Absorbance of the resulting solution was measured at $550 \mathrm{~nm}$, against blank experiment. Calibration curves relating the absorbance at $550 \mathrm{~nm}$ to GF or DR concentrations were plotted and regression analysis of the results was computed.

\subsubsection{Assay of Dosage Forms}

Muclear Capsules. The well mixed powdered content of five capsules was used in the assay. An amount equivalent to $10 \mathrm{mg}$ of GF was transferred into $100 \mathrm{~mL}$ volumetric flask, dissolved in distilled water then adjusted to volume and treated as previously mentioned under calibration procedure.

Tussapine Lozenges. Five tablets were grounded to a homogenous fine powder, weighed and the average mass per tablet was determined. The amount of powder equivalent to $10 \mathrm{mg}$ of DR was dissolved into $70 \mathrm{~mL}$ of distilled water. The solution was sonicated for about five minutes then filtered to separate insoluble excipients. Afterwards, the filtrate was accurately collected into $100 \mathrm{~mL}$ calibrated flask and diluted to volume with water. The obtained solution labeled to contain $0.1 \mathrm{mg} \mathrm{mL}^{-1}$ of each drug was analyzed by the proposed method as detailed under calibration.

\section{Results and Discussion}

s-Triazoles have been utilized to produce reagents that can react with drugs containing carbonyl group or susceptible to oxidation with periodic acid to produce carbonyl function such as diols and amino alcohols. In the present work, guaifenesin and dropropizine were converted into formaldehyde and the corresponding carboxylic acids by the selective oxidizing effect of periodic acid. The liberated aldehyde was allowed to react with 4-Amino-5-hydrazino-4H [1,2,4]triazole-3-thiol, which is a specific reagent for aldehydic functional group [16].

When AHTT was allowed to condense with formaldehyde followed by treatment with periodic acid and alkali addition, [1,2,4]-triazolo- $[1,2,4,5]$ tetrazine-3-thiol colored product was obtained as shown in Scheme 1.

3.1. Optimization of Conditions. As reported by Jacobsen and Dickinson [16], the reaction involves the addition of alkaline solution of AHTT to the aldehyde solution and aerating the reaction mixture to give a purple-colored product. Mimura et al. [17] modified the procedure of color development by the use of periodic acid as oxidizing agent instead of aeration.

In the present study, periodic acid has a dual function. It acts as a selective oxidizing agent for polyhydroxy compounds to convert them to formaldehyde and corresponding carboxylic acids and help in the development of the purple colored product according to Mimura et al. [17] modification. It is important to emphasize that Jacobsen and Dickinson [16] used alkaline solution of AHTT (1\% in $1 \mathrm{M}$ $\mathrm{NaOH}$ ) for color production with aldehydes. However, this procedure was modified by using acidic solution of AHTT 

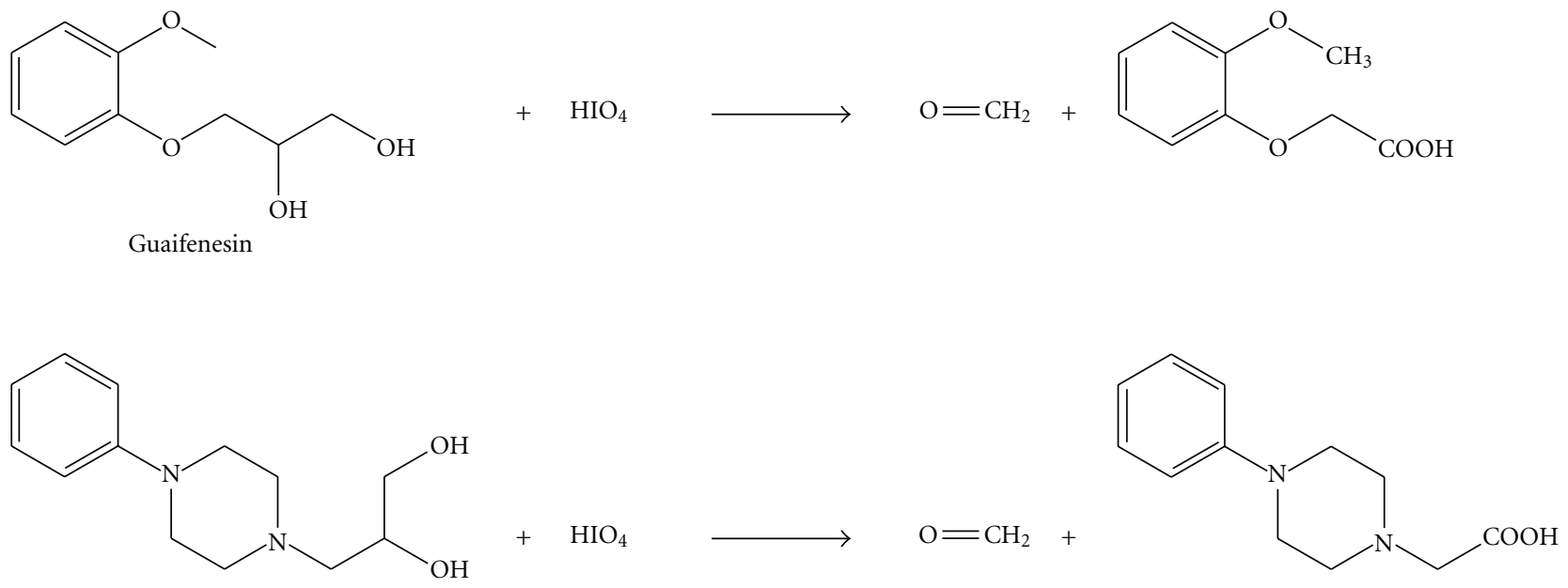

Dropropizine

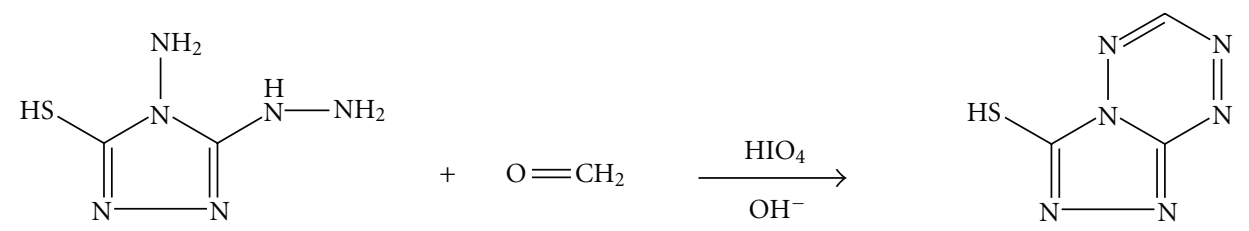

AHTT

Scheme 1: Reactions involved in analysis of guaifenesin and dropropizine.

$(0.5 \%$ in $0.5 \mathrm{M} \mathrm{HCl})$ which offers two advantages, the first was the use of lower concentration of the reagent; the second was the higher stability of AHTT solution as mentioned by Mimura et al. [17].

As reported for colorimetric determination of some diol-containing drugs [18], solution of guaifenesin and dropropizine was left for some time, then $5 \mathrm{M} \mathrm{KOH}$ and AHTT solutions were added whereby a purple color was developed with maximum absorption at $550 \mathrm{~nm}$ (Figures 1 and 2). Maximum color intensity was obtained when periodic acid solution was made to react with guaifenesin for 15 minutes and dropropizine for 20 minutes.

The effect of periodic acid concentration was also studied, it was found to be critical the use of $1 \mathrm{mg} \mathrm{mL}^{-1}$ solution of periodic acid in $0.2 \mathrm{M} \mathrm{KOH}$ produces maximum color intensity. Excess acid concentration causes a great decrease in the intensity of the produced color which may be attributed to the strong oxidizing effect of periodic acid on both drugs which may proceed to give further oxidation products.

The effect of AHTT concentration was also studied where maximum intensity was obtained upon using AHTT solution of $0.5 \%$ in $0.5 \mathrm{M} \mathrm{HCl}$.

Volume of $\mathrm{KOH}$ added was found to be critical; $0.5 \mathrm{~mL}$ of $5 \mathrm{M}$ alkali solution was the optimum volume.

Shaking of the reaction mixture for 4-5 minutes was essential and produced maximum color intensity after addition of AHTT solution and waiting period of 15 minutes for GF and 20 minutes for DR. The obtained color remained stable for about 40 minutes with both drugs.

\subsection{Method Validation}

3.2.1. Linearity, Detection, and Quantitation Limits. Calibration curves representing the relation between each drug concentrations and absorbance of colored products were constructed. Results show linear relationship in the range of 5-45 $\mu \mathrm{g} \mathrm{mL}^{-1}$ for GF and $10-80 \mu \mathrm{g} \mathrm{mL}^{-1}$ for DR; in triplicate measurement from which linear regression equations were calculated. Correlation coefficient, slope and intercept were listed in Table 1. Results indicate high sensitivity of the proposed method.

According to ICH recommendation [19], the approach based on the S.D. of the response and the slope was used for determining the detection and quantitation limits. The theoretical values were assessed practically and given in Table 1.

3.2.2. Accuracy. Accuracy of the measurements was determined using the calibration standards of two drugs, where mean percentage of 100.58 for GF and 100.22 for DR were obtained, results are shown in Table 1 . Accuracy was also assessed by the recovery of added standard, three concentrations each in duplicate to know concentration 
TABLE 1: Selected spectral data for the determination of guaifenesin and dropropizine by the proposed colorimetric method.

\begin{tabular}{lcc}
\hline Parameters & GF & DR \\
\hline Linearity range $\left(\mu \mathrm{g} \mathrm{mL}^{-1}\right)$ & $5-45$ & $10-80$ \\
Slope \pm S.E & $0.021 \pm 3.7 \mathrm{E}-04$ & $0.011 \pm 1.77 \mathrm{E}-04$ \\
Intercept \pm S.E. & $0.014 \pm 0.0109$ & $0.039 \pm 0.0089$ \\
Correlation coefficient & 0.998 & 0.998 \\
Accuracy \pm S.D. precision & $100.58 \pm 0.48$ & $100.22 \pm 1.36$ \\
Injection repeatability $(n=15)$ & $0.80-1.26$ & $0.14-0.38$ \\
Assay reproducibility intraday $(n=9)$ & Muclear & Tussapine \\
& $0.40 \%-1.79 \%$ & $0.13 \%-0.28 \%$ \\
Interday $(n=27)$ & Muclear & Tussapine \\
LOQ $^{\mathrm{a}}\left(\mu \mathrm{g} \mathrm{mL}^{-1}\right)$ & $1.01 \%-1.72 \%$ & $0.39 \%-0.73 \%$ \\
$\mathrm{LOD}^{\mathrm{a}}\left(\mu \mathrm{g} \mathrm{mL}^{-1}\right)$ & 4 & 7 \\
\hline
\end{tabular}

a $\mathrm{LOQ}$ and LOD were done practically.

TABLE 2: Statistical analysis of the results obtained by applying the proposed, reported and manufacturer methods for the analysis of GF and DR in their dosage forms.

\begin{tabular}{|c|c|c|c|}
\hline Preparation & Proposed & Reported & Manufacturer \\
\hline \multirow{3}{*}{ Muclear } & $100.34 \pm 0.89 *$ & $101.18 \pm 0.76$ & - \\
\hline & $F=2.71$ & - & \\
\hline & $t=0.55$ & - & \\
\hline Standard addition & $99.39 \pm 1.36^{* *}$ & & \\
\hline \multirow{3}{*}{ Tussapine } & $100.29 \pm 0.76^{*}$ & - & $100.23 \pm 0.84$ \\
\hline & $F=1.55$ & & - \\
\hline & $t=0.33$ & & - \\
\hline Standard addition & $100.60 \pm 1.05^{* *}$ & & \\
\hline
\end{tabular}

* Mean of nine determinations (three conc. each in triplet).

** Mean of six determinations (two for each of conc.).

of dosage forms using the proposed colorimetric method. Results of mean \% recovery for added standards in each formulation are reported in Table 2 .

3.2.3. Precision. Repeatability and reproducibility of the instrumental response (absorbance of the formed color) were checked during method development and they were assessed from five replicate determinations of sample solutions of GF and $\mathrm{DR}$ at the concentration of $30 \mu \mathrm{g} \mathrm{mL}^{-1}$.

3.2.4. Specificity. The proposed method was applied for the determination of both drugs in their pharmaceutical formulations; results presented in Table 2 revealed that there is no interference from excipients, additives or coformulated drugs such as bromhexine $\mathrm{HCl}$ present in Muclear capsules along with guaifenesin. In addition the recoveries of the studied drugs from their formulations were almost the same as the recoveries of the pure added when applying the standard addition technique.

Results obtained by the proposed method were statistically compared with those obtained from the reported HPLC method for GF [5] and UV manufacturer method for DR.

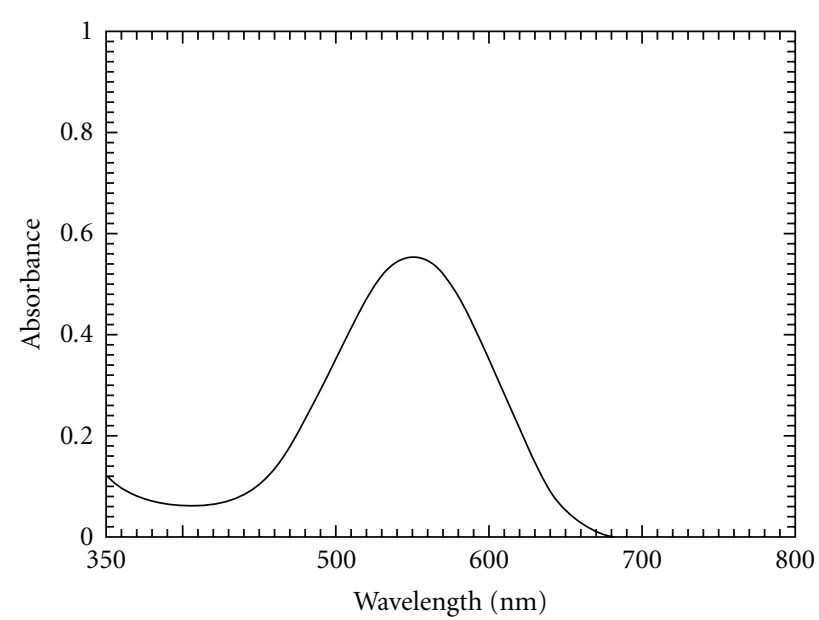

FIGURE 1: Absorbance spectrum of the colored product produced from the reaction of AHTT and $30 \mu \mathrm{g} \mathrm{mL}^{-1}$ guaifenesin.

The calculated $t$ and $F$ values are less than the tabulated ones indicating no significant difference between the proposed 


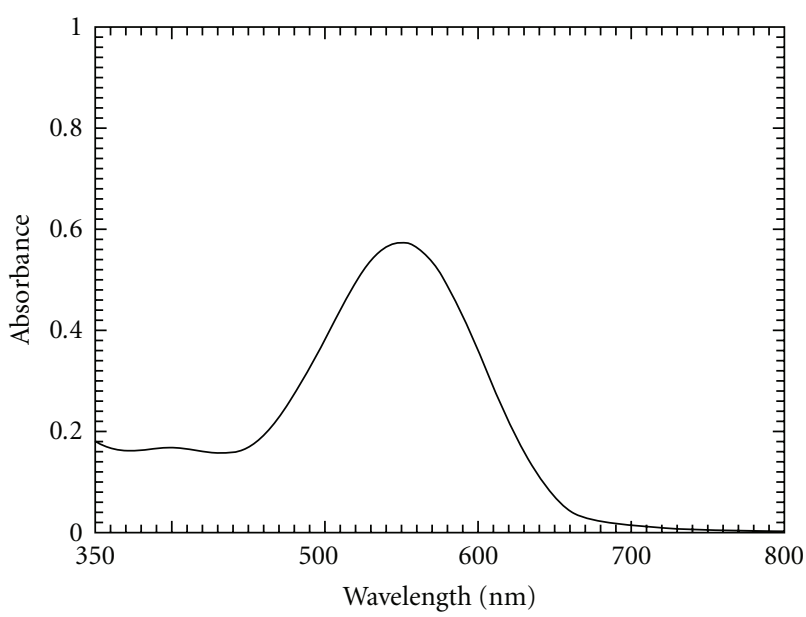

FIGURE 2: Absorbance spectrum of the colored product produced from the reaction of AHTT and $40 \mu \mathrm{g} \mathrm{mL}^{-1}$ dropropizine.

and reported methods with respect to accuracy and precision at $95 \%$ confidence limit (Table 2).

\section{Conclusion}

The proposed colorimetric method is selective for polyhydroxy aliphatic compounds, simple and rapid as it takes from 15 to 20 minutes for the sample to be ready for measurement. Validation of the proposed method was carried out according to the ICH guidelines. The short duration of the assay and its specificity were clear bonuses for routine analysis of guaifenesin and dropropizine in their pharmaceutical formulations and in-process quality control.

\section{References}

[1] P. Khathleen, Martindale: The Complete Drug Reference, (PhP) Pharmaceutical Press, London, UK, 32nd edition, 1999.

[2] S. M. Amer, S. S. Abbas, M. A. Shehata, and N. M. Ali, "Simultaneous determination of phenylephrine hydrochloride, guaifenesin, and chlorpheniramine maleate in cough syrup by gradient liquid chromatography," Journal of AOAC International, vol. 91, no. 2, pp. 276-284, 2008.

[3] M. Vasudevan, S. Ravisankar, M. George, and J. Ravi, "Simultaneous estimation of terbutaline, bromhexine and guaiphenesin in soft gelatin capsules by HPLC method," Indian Drugs, vol. 37, no. 10, pp. 489-492, 2000.

[4] V. Galli and C. Barbas, "High-performance liquid chromatographic analysis of dextromethorphan, guaifenesin and benzoate in a cough syrup for stability testing," Journal of Chromatography A, vol. 1048, no. 2, pp. 207-211, 2004.

[5] M. L. Wilcox and J. T. Stewart, "HPLC determination of guaifenesin with selected medications on underivatized silica with an aqueous-organic mobile phase," Journal of Pharmaceutical and Biomedical Analysis, vol. 23, no. 5, pp. 909-916, 2000.

[6] L. A. Shervington, "A quantitative simultaneous high performance liquid chromatographic determination of pseudoephedrine $\mathrm{HCl}$, guaifenesin and dextromethorphan $\mathrm{HBr}$," Analytical Letters, vol. 30, no. 5, pp. 927-944, 1997.
[7] T. D. Wilson, W. G. Jump, W. C. Neumann, and T. San Martin, "Validation of improved methods for high-performance liquid chromatographic determination of phenylpropanolamine, dextromethorphan, guaifenesin and sodium benzoate in a cough-cold formulation," Journal of Chromatography, vol. 641, no. 2, pp. 241-248, 1993.

[8] S. Stavchansky, S. Demirbas, L. Reyderman, and C.-K. Chai, "Simultaneous determination of dextrorphan and guaifenesin in human plasma by liquid chromatography with fluorescence detection," Journal of Pharmaceutical and Biomedical Analysis, vol. 13, no. 7, pp. 919-925, 1995.

[9] T. Harsono, M. Yuwono, and G. Indrayanto, "Simultaneous determination of some active ingredients in cough and cold preparations by gas chromatography, and method validation," Journal of AOAC International, vol. 88, no. 4, pp. 1093-1098, 2005.

[10] M. H. M. Sharaf and D. D. Stiff, "Determination of guaifenesin in human serum by capillary gas chromatography and electron capture detection," Journal of Pharmaceutical and Biomedical Analysis, vol. 35, no. 4, pp. 801-806, 2004.

[11] Y. Tanaka, Y. Kishimoto, K. Otsuka, and S. Terabe, "Strategy for selecting separation solutions in capillary electrophoresismass spectrometry," Journal of Chromatography A, vol. 817, no. 1-2, pp. 49-57, 1998.

[12] T. Grygar, O. Frýbort, P. Bezdička, and T. Pekárek, "Quantitative analysis of antipyretics and analgesics in solid dosage forms by powder X-ray diffraction," Chemia Analityczna, vol. 53, no. 2, pp. 187-200, 2008.

[13] I. Tapsoba, J.-E. Belgaied, and K. Boujlel, "Voltammetric assay of Guaifenesin in pharmaceutical formulation," Journal of Pharmaceutical and Biomedical Analysis, vol. 38, no. 1, pp. 162-165, 2005.

[14] R. F. Staack, D. S. Theobald, and H. H. Maurer, "Studies on the human metabolism and the toxicologic detection of the cough suppressant dropropizine in urine using gas chromatographymass spectrometry," Therapeutic Drug Monitoring, vol. 26, no. 4, pp. 441-449, 2004.

[15] P. Zaratin, L. De Angelis, and F. Cattabeni, "Gas chromatographic-mass spectrometric determination of levodropropizine plasma levels in healthy volunteers," Arzneimittel-Forschung, vol. 38, no. 8, pp. 1156-1158, 1988.

[16] N. W. Jacobsen and R. G. Dickinson, "Spectrometric assay of aldehydes as 6-mercapto-3-substituted-s-triazolo(4,3-b)-stetrazines," Analytical Chemistry, vol. 46, no. 2, pp. 298-299, 1974.

[17] H. Mimura, M. Kanebo, N. Nishigams, S. Fukui, and S. Kanno, "The determination of formaldehyde by the 4-amino-3hydrazino-5-mercapto-1,2,4-triazole method," Eisei Kagaku, vol. 22, p. 39, 1967, Through Chemistry Abstract, vol. 85, article 71809, 1976 .

[18] O. M. Abdullah and S. E.-S. Barakat, "Spectrophotometric determination of glucosamine and mannitol with 4-amino5-hydrazino-4H[1,2,4]-triazole-3-thiol in pharmaceutical formulations," Saudi Pharmaceutical Journal, vol. 13, no. 4, pp. 185-191, 2005.

[19] The European Agency for the Evaluation of Medical Products, "ICH Topic Q2B Note for Guidance on Validation of Analytical Procedures," Methodology GPMP/ICH/1995, pp. 281- 295. 


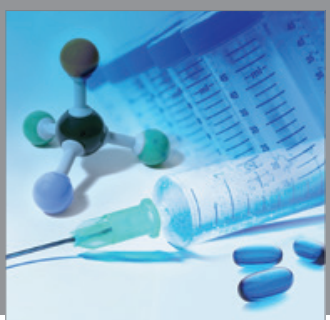

International Journal of

Medicinal Chemistry

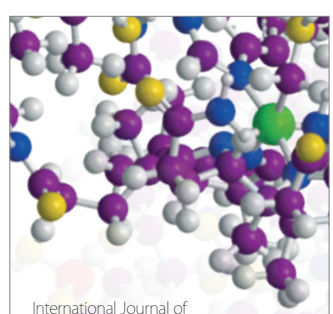

Carbohydrate Chemistry

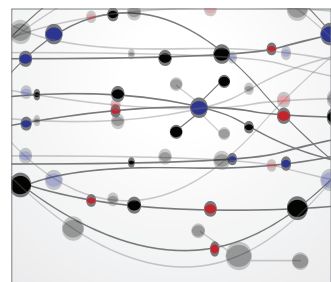

The Scientific World Journal
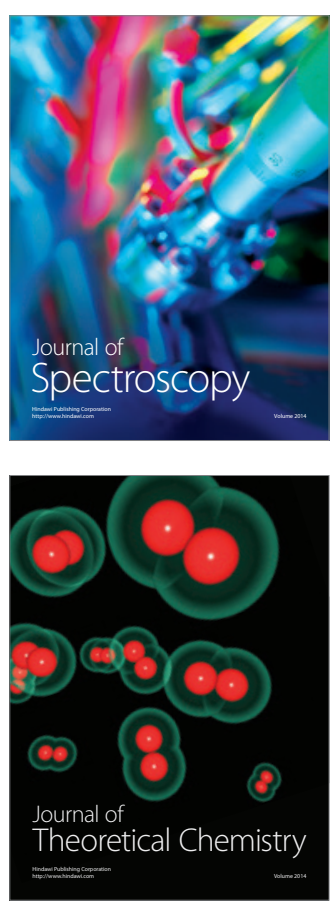
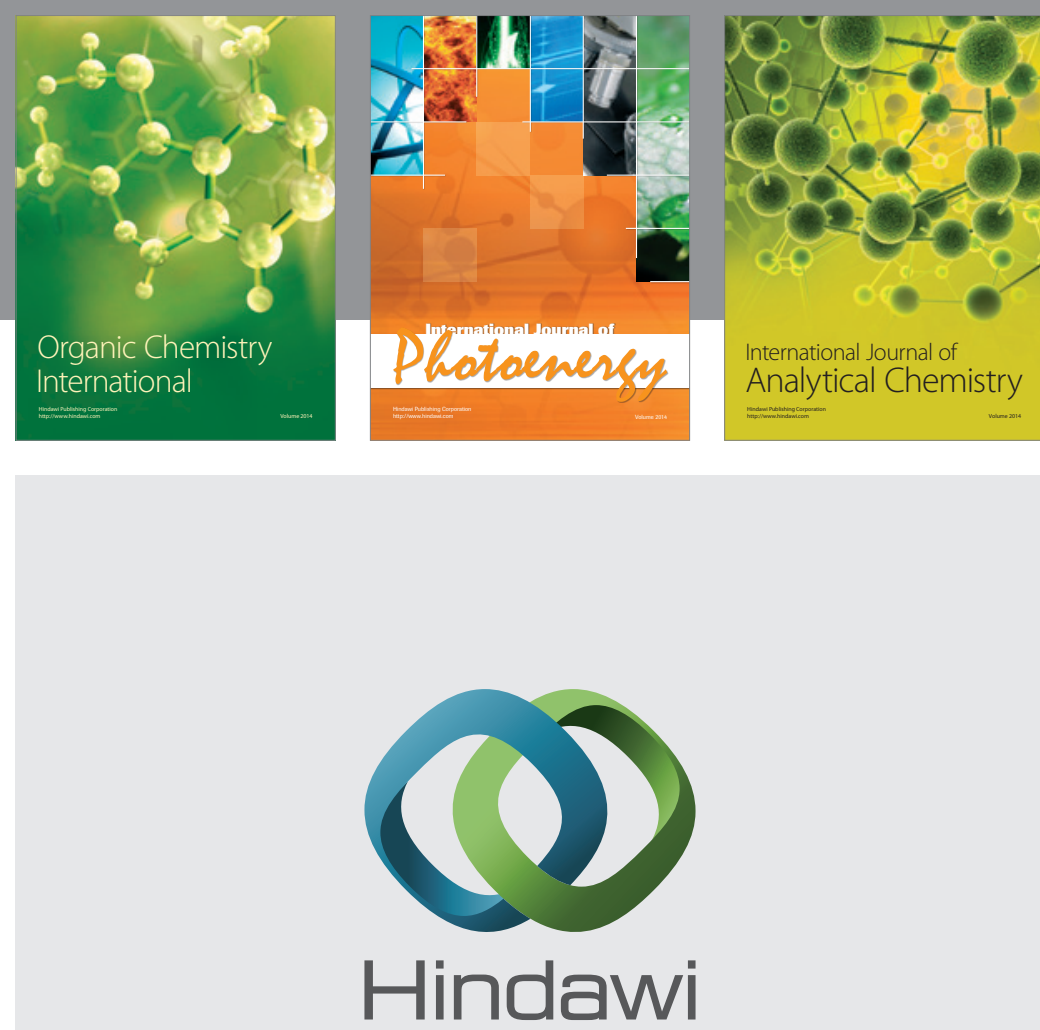

Submit your manuscripts at

http://www.hindawi.com
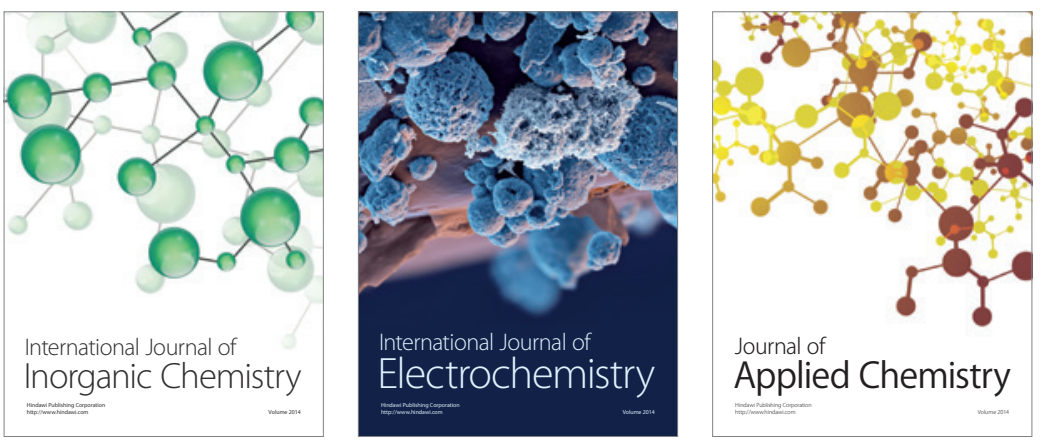

Journal of

Applied Chemistry
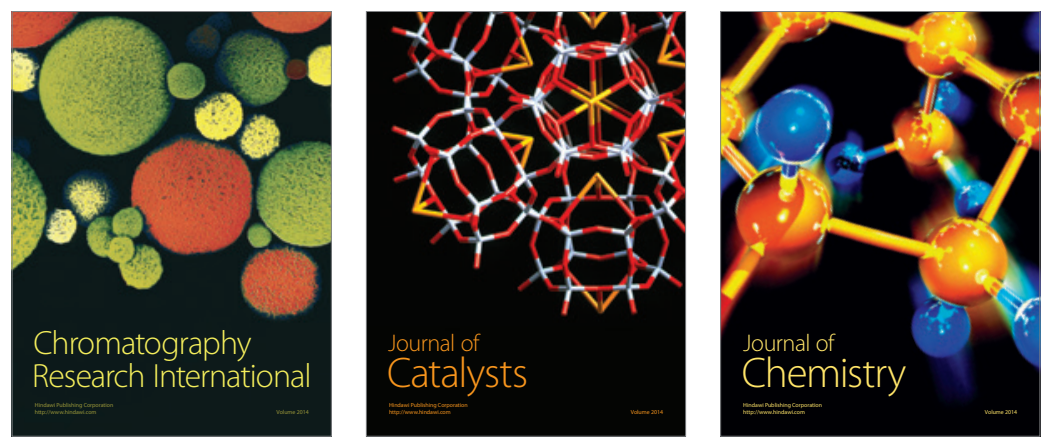
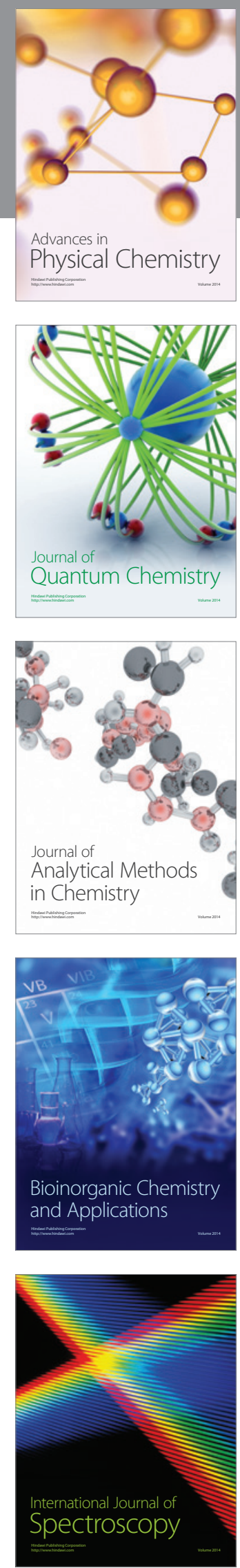